\title{
A Thermodynamic Study of Air Cycle Machine for Aeronautical Applications
}

\author{
A.P.P. Santos, C.R. Andrade*, E.L. Zaparoli \\ Instituto Tecnológico de Aeronáutica - Aeronautical Division \\ Pça Marechal Eduardo Gomes, 50 - 12228-900 - São José dos Campos, SP, Brasil \\ Email: ${ }^{*}$ claudia@ita.br
}

\begin{abstract}
This work focuses on a thermodynamic study of an air cycle machine (ACM) for aircraft air-conditioning purposes. The ACM configuration mainly includes two compact heat exchangers, a compressor and an expander. The energy to drive this machine comes from the compressed air bleed from the compressor of the aircraft propulsion turbine. Some design features that affect the ACM performance will be studied: aircraft Mach number, cabin altitude, cabin recirculated air temperature and the percentage of the turbine work absorbed by the exhaust fan. Results showed that the computational tool implemented to solve the ACM mathematical model allows an understanding of the air cycle machine performance when flight aircraft and cabin human comfort parameters are changed to attain an optimized aircraft environmental control system (ECS) design.
\end{abstract}

Keywords: Air-conditioning; air cycle machine (ACM); environmental control system (ECS); coefficient of performance (COP).

\section{Introduction}

Environmental control system (ECS) is a generic term used in the aircraft industry for the systems and equipment associated with the ventilation, heating, cooling, humidity/contamination control, and pressurization in the occupied compartments, cargo compartments, and electronic equipment bays [1].

The primary function of the cabin air conditioning and pressurization system is to maintain an aircraft environment that will ensure the safety and comfort of the passengers and crew during all flight operational conditions and provide adequate avionics cooling. This includes a supply of conditioned air for heating and cooling the cockpit and cabin spaces [2]. Therefore, the aircraft air-conditioning packs must provide essentially dry, sterile, and dust free conditioned air to the airplane cabin at the proper temperature, flow rate, and pressure to satisfy these pressurization and temperature control requirements [3]. Also aircraft systems must be light, accessible for quick inspection and servicing, highly reliable, tolerant of a wide range of environmental conditions, able to withstand aircraft vibratory and maneuver loads, and able to accommodate failures occurring during flight [1]. Hence, design conditions for aircraft purposes differ in several ways from other air conditioning applications [4].

Air cycle refrigeration is a tried and tested technology that has long been the basis of aircraft cabin cooling since air is free, safe and harmless to the environment. The use of air as a refrigerant is based on the principle that when a gas expands isentropically from a given temperature, its final temperature at the new pressure is much lower. The resulting cold gas can then be used as a refrigerant, either directly in an open system, or indirectly by means of a heat exchanger in a closed system. The efficiency of such systems is limited to a great extent by the efficiencies of compression and expansion, as well as those of the heat exchangers employed.
Hence, the air cycle machine has evolved as a widely used means of providing cooling for aircraft and helicopters [5]. Compressed air extracted from one or more stages of the engine compressor expands through a turbine with the power extracted used to drive a fan (simple cycle), a compressor (bootstrap cycle), or both (simple/bootstrap cycle). The power extraction and expansion of the compressor air across the turbine results in a significant temperature decrease. This air provides cooling for the aircraft occupied compartments and avionics. Some of the bleed air from the engines can be bypassed around the airconditioning pack if warm is need in the cabin [6].

It is well known that weight and space results in severe fuel penalties for aircraft applications. Air cycle machine presents lower coefficient of performance (refrigerating effect unit per required power) than a vapor-compression system but provides weight advantages due to no heat exchanger required at the cold cycle end (low pressure/temperature), as detailed in [7]. Moreover, a common turbo compressor for both the propulsion turbine and refrigeration plant results in a greater overall power saving.

Some additional advantages of an air cycle with regard to its application in aircraft refrigeration can be listed as follows [8]:

i. High ventilation rate necessary for the pressurized aircraft cabin.

ii. High flow rate of compressed air for cabin pressurization.

iii. Part of compression work can be attributed to cabin pressurization (also necessary if other refrigeration cycle is used).

iv. One equipment for cooling/heating load (an independent heating equipment is necessary for another refrigeration cycle).

v. The cabin air-conditioning/pressurization integration 
Several features of air-cycle refrigeration machine have been recently investigated. Leo and Perez-Grande [9] performed a thermoeconomic analysis of a commercial aircraft environmental control system. These authors showed that a minimum cost can been found at a pressure close to the ACM nominal bleed pressure. Conceição et al. [10] developed a thermodynamic model of an air-cycle machine under flight and ground operating conditions. Their results showed that the thermodynamic advantages of the four-wheel in relation to the three-wheel machine are maximized when considering critical cooling conditions for hot days. Al-Garni et al. [11] presented a tool for extracting management information from field failures of aircraft cooling systems. Their techniques allow engineers to quickly identify failure trends, misbehaving systems, unusual behaviors, and effects of environmental conditions, maintenance practices, and repair actions for ECS system maintenance.

In the work of Zhao et al. [12], an experimental study on the off-design performance and dynamic response of an aircraft environmental control system (ECS) has been conducted. A bootstrap air cycle refrigeration system with high pressure water separation was employed and both the static and the dynamic tests were performed. Tu and Lin [13] showed that the thermal dynamic responses of the aircycle cooling pack is sensible to the temperature and the mass-flow-rate change of bleed air and ram air. Yoo et al. [14] developed an air-cycle machine modeling program including a phase change heat exchanger to estimate its effect in various aircraft flight conditions such as take-off, maneuver, cruise, and landing.

In this context, the present work focuses on the numerical simulation of the air cycle machine changing some aircraft flight and human comfort parameters as Mach number, cabin altitude and cabin recirculated air temperature. Results hereby obtained allow a better understanding about the influence of these parameters on the ACM performance, and leading to identification of relevant conditions to attain an optimized ECS design.

\section{Flight Scenario and Air Cycle Machines}

Cabin altitude and pressure changes are much smaller in magnitude on today's high altitude pressurized jets than they were during past flights. Although the percentage of oxygen in cabin air remains virtually unchanged (21 percent) at all normal flight altitudes compared to sea level, the partial pressure of oxygen decreases with increasing altitude. This is because with increasing altitude air is less densely packed, resulting in fewer molecules of oxygen available for each occupant breathing cycle [15].

At a maximum cabin altitude of 8,000 feet, the partial pressure of oxygen is about 74 percent of the sea level value requiring an adequate pressurization system to maintain a suitable comfort level to the passengers and crew. A typical flight will cruise at 36,000 feet $(\sim 11,000 \mathrm{~m})$, resulting in a cabin altitude of 6,000 feet $(\sim 1,800 \mathrm{~m})$. Figure 1 shows a typical cabin and airplane altitudes schedule.

An air-conditioning pack is an air cycle refrigeration system that uses the air passing through and into the airplane as the refrigerant fluid. Fresh air is bled from the compression stages of the engine and supplied, after conditioning, to the cabin to control such factors as temperature, pressure, and contaminant level, which may greatly influence passengers' perceptions of the cabin environment [16]. This is accomplished by a combined turbine and compressor machine, valves for temperature and flow control, and heat exchangers using outside air to dispense waste heat. The ACM must provide essentially dry, sterile, and dust free conditioned air to the airplane cabin at the proper temperature, flow rate, and pressure to satisfy pressurization and temperature control requirements [15].

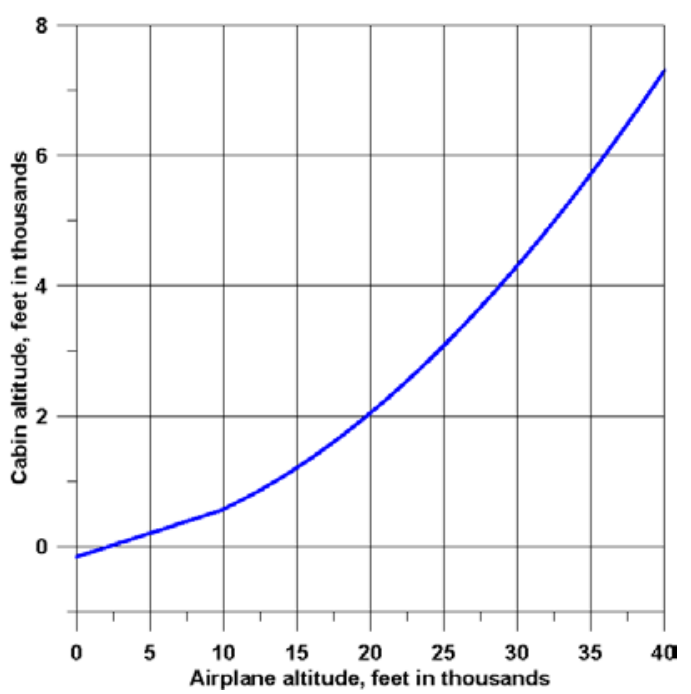

Figure 1. Typical cabin and airplane altitudes schedule.

There are three basic configurations of ACM where compressed air extracted from one or more stages of the propulsion turbine compressor is cooled (by one or more heat exchangers) and expanded through a turbine. The power supplied by the ACM turbine may be used to drive a fan (simple cycle, Figure 2a), a compressor (bootstrap cycle, Figure 2b), or both (simple/bootstrap cycle, Figure 2c).

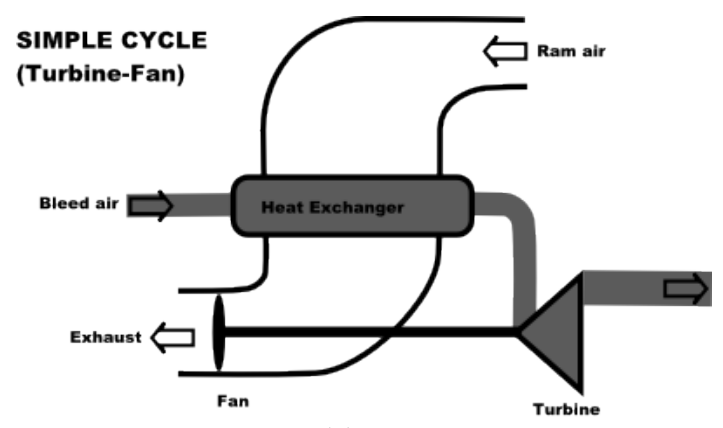

(a)

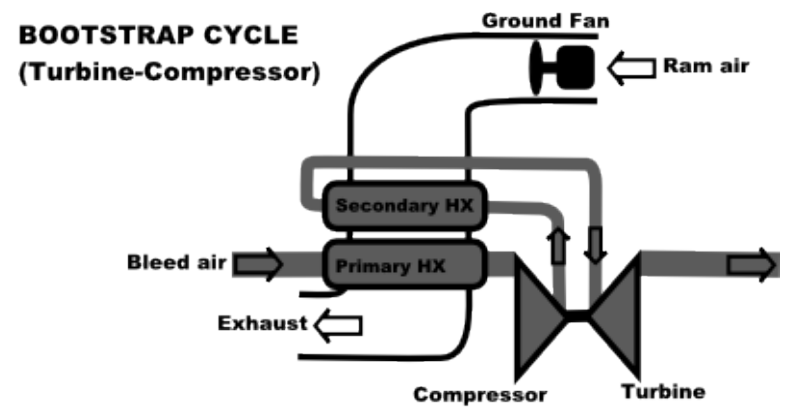

(b) 


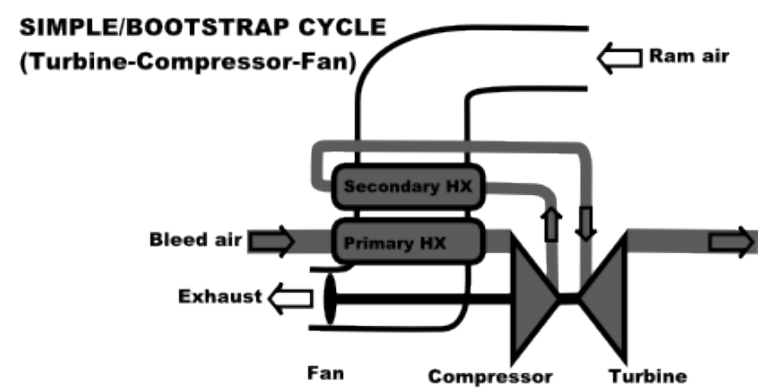

(c)

Figure 2. Air cycle machines representation: (a) simple cycle; (b) bootstrap cycle; (c) simple/bootstrap cycle.

In the simple cycle, all the ACM turbine work is consumed by the heat exchanger exhaust fan while in the full bootstrap cycle this power work is used only to drive the ACM compressor. A mixed configuration (simple/bootstrap) is achieved by sharing part of the ACM turbine useful work between the ACM compressor and the exhaust fan.

According to Wright et al [17], there is very little publications specifically aimed to aircraft air-conditioning systems. Details of air cycle machine architectures are usually confidential information belonging to manufactures and scarcely available within open literature. Thus, the main contribution of the present work is to present a threewheel bootstrap ACM study by means of a well-known thermodynamic modeling.

\section{Thermodynamic Modeling}

A typical open bootstrap air cycle machine processes (17) can be plotted in a temperature $x$ entropy diagram, as schematized in Figure 3.

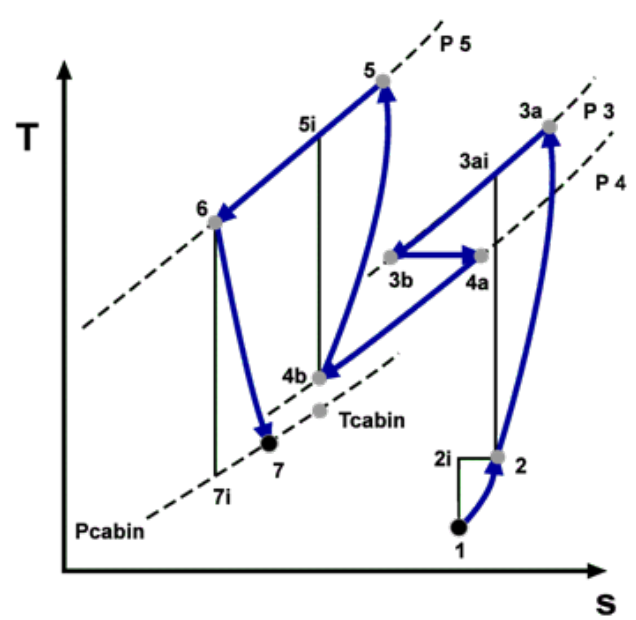

Figure 3. Processes of an aircraft bootstrap ACM.

where:

1 ambient static conditions;

2 state after ram air compression;

3a propulsion turbine compressor (primary

compressor) exit;

$3 \mathrm{~b} \quad$ bleed pre-cooler (heat exchanger) exit;

4a bleed pressure control valve exit;

4b ACM primary heat exchanger exit;

5 ACM compressor (secondary compressor) exit;

6 ACM secondary heat exchanger exit;

$7 \quad$ ACM turbine exit;

i isentropic process exit; cabin cabin pressure and cabin recirculated air temperature.

When the aircraft is flying, the initial compression of the ambient air is due to ram effect. The ram effect is shown by line 1-2. Point 1 represents the static temperature and pressure of external ambient air, while point $2 \mathrm{i}$ denotes the state after isentropic compression to pressure $P_{2 i}$ and temperature $T_{2 i}$ so that we have from the energy equation:

$h_{2}=h_{1}+\frac{V_{1}^{2}}{2}$

where: $h_{1}=$ static air enthalpy, $V_{1}=$ aircraft velocity.

Assuming air as a perfect gas with constant specific heat [18] and using Eq.(1), the following result can be obtained:

$T_{2}=T_{2 i}=T_{1}+\frac{V_{1}^{2}}{2 C_{p}}$

The above relation can be modified such that the Mach number appears:

$\frac{T_{2}}{T_{1}}=1+\frac{(k-1) M^{2}}{2}$

where:

$k=C_{\mathrm{p}} / C_{\mathrm{v}}=$ specific heat at constant pressure to specific heat at constant volume ratio;

$M=$ Mach number of the aircraft flight $=V_{1} / a$;

$a=$ sound velocity.

The stagnation pressure after isentropic compression $P_{2 i}$, is given by the relation:

$\frac{P_{2 i}}{P_{1}}=\left(\frac{T_{2 i}}{T_{1}}\right)^{\frac{k}{k-1}}$
$\eta_{r}=\frac{P_{2}-P_{1}}{P_{2 i}-P_{1}}=\frac{\text { actual pressure recovery }}{\text { ideal pressure recovery }}$

The ram work $\left(W_{r}\right)$ which is obtained directly from the engine (drag penalty) is evaluated by:

$W_{r}=\dot{m} C_{p}\left(T_{2}-T_{1}\right)$

where $\dot{m}=$ mass flow rate.

The initial compressed air required to drive the ACM is bleed of the aircraft engine, as shown in Figure 4. This first compression occurs at the propulsion turbine compressor, process 2-3a. For the ideal isentropic process $2-3 \mathrm{i}$ the temperature at the point $3 \mathrm{i}$ is calculated as:

$\frac{T_{3 a i}}{T_{2}}=\left(\frac{P_{3}}{P_{2}}\right)^{\frac{k-1}{k}}$

where $P_{3}=$ compressor bleed port pressure. 


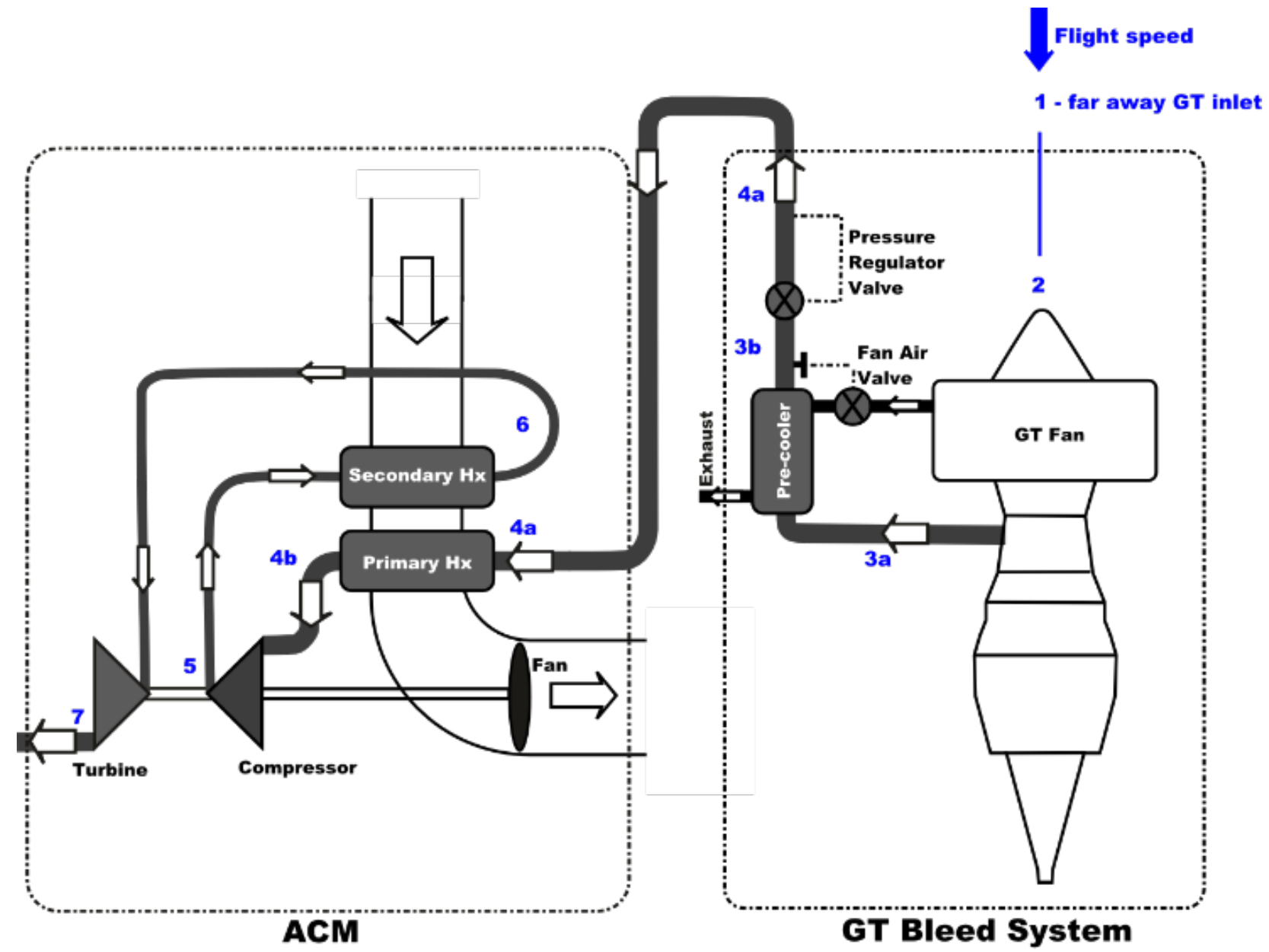

Figure 4. Typical architecture of the ACM and the gas turbine (GT) bleed system showing the pre-cooler and the pressure regulator valve.

Temperature at the point 3a (primary compressor bleed port) is determined knowing the value of the primary compressor isentropic efficiency, defined by:

$$
\eta_{p c}=\frac{T_{3 a i}-T_{2}}{T_{3 a}-T_{2}}=\frac{\text { ideal primary compressor work }}{\text { actual primary compressor work }}
$$

The actual primary compressor work can be calculated by:

$W_{p c}=\dot{m} C p\left(T_{3 a}-T_{2}\right)=\frac{\dot{m} C p T_{2}}{\eta_{p c}}\left[\left(\frac{P_{3}}{P_{2}}\right)^{\frac{k-1}{k}}-1\right]$

The aircraft bleed system initially controls the temperature and pressure of the compressed air as shown in Figure 4. The state of compressed air supplied to the air cycle machine is represented by point 4a in $T$ vs $S$ diagram shown in Figure 3 and also in Figure 4 (primary heat exchanger entry). The temperature drop in the pneumatic system pre-cooler (3a-3b) does not represent a performance penalty but the pressure reduction through the pneumatic pressure control valve (3b-4a) causes a lost in the cooling effect.

In the process $4 a-4 b$ the working fluid (air) is cooled by the ACM primary heat exchanger. Pressure $P_{4 a}$ is equal to $P_{4 b}$ if the fluid friction process is neglected. So, the amount of heat rejected in the ACM primary heat exchanger $\left(Q_{\mathrm{phx}}\right)$ is:

$$
Q_{p h x}=\dot{m} C_{p}\left(T_{4 a}-T_{4 b}\right)
$$

Temperature state $T_{4 b}$ is calculated taking account the primary heat exchanger effectiveness $\left(\varepsilon_{p h x}\right)$ given by:

$\varepsilon_{p h x}=\frac{T_{4 a}-T_{4 b}}{T_{4 a}-T_{2}}$

assuming that the heat sink (ram air) temperature of the primary heat exchanger is equal to $T_{2}$. Remember that the temperature after the cooling process $4 \mathrm{a}-4 \mathrm{~b}$ must be higher than the stagnation temperature $T_{2}$ of the ambient air. It implies that the working fluid cannot be cooled by heat exchange to a temperature bellow $T_{2}$.

Temperature at the point $5 \mathrm{i}$, after the isentropic compression through the ACM secondary compressor, is calculated as:

$\frac{T_{5 i}}{T_{4 b}}=\left(\frac{P_{5}}{P_{4 b}}\right)^{\frac{k-1}{k}}$

Given the value of the secondary compressor isentropic efficiency, the temperature at the point 5 can be determined as: 
$\eta_{s c}=\frac{T_{5 i}-T_{4 b}}{T_{5}-T_{4 b}}=\frac{\text { ideal sec ondary compressor work }}{\text { actual secondary compressor work }}$

The actual secondary compressor work can be calculated by:

$W_{s c}=\dot{m} C_{p}\left(T_{5}-T_{4 b}\right)=\frac{\dot{m} C_{p} T_{4 b}}{\eta_{s c}}\left[\left(\frac{P_{5}}{P_{4}}\right)^{\frac{k-1}{k}}-1\right]$

In the process 5-6 the working fluid (air) is cooled by the ACM secondary heat exchanger. If the fluid friction process is neglected, pressure $P_{5}$ is equal to $P_{6}$. The amount of heat rejected in the ACM secondary heat exchanger $\left(Q_{\text {shx }}\right)$ is:

$Q_{s h x}=\dot{m} C_{p}\left(T_{5}-T_{6}\right)$

where T6 is calculated taking account the secondary heat exchanger effectiveness $\left(\varepsilon_{s h x}\right)$ given by:

$\varepsilon_{\text {shx }}=\frac{T_{5}-T_{6}}{T_{5}-T_{2}}$

assuming that the minimum attainable temperature for the working fluid is the ram air temperature.

The largest temperature drop occurs when the air expands in the turbine (expander) of the air cycle machine. (see Figure 4). In the isentropic process the state at the end of expansion process is represented by point $7 \mathrm{i}$ in $T$ vs $\mathrm{s}$ diagram (Figure 3 ). For the actual conditions, the pressure $P_{7 \mathrm{i}}=P_{7}$ is slightly above the pressure of aircraft pressurized cabin $\left(P_{\text {cabin }}\right)$ that is higher than the external ambient pressure. So, in the present work, it is assumed that $P_{7}=P_{\text {cabin }}$, neglecting the pressure drop in the air distribution ducts.

Pressure $P_{5}$ (equal to $P_{6}$ ) is determined solving the implicit equation obtained from the ACM work balancing: the ACM turbine work is equal to the sum of the secondary compressor work and the exhaust fan work.

Temperature $T_{7 \mathrm{i}}$ can be calculated by the isentropic relation:

$\frac{T_{7 i}}{T_{6}}=\left(\frac{P_{7}}{P_{6}}\right)^{\frac{k-1}{k}}$

Due to expansion irreversibilities, temperature $T_{7}$ is greater than $T_{7 i}$ reducing the expander temperature drop. The temperature $T_{7}$ at the end of the actual expansion process can be calculated knowing the turbine isentropic efficiency $\left(\eta_{t}\right)$ :

$\eta_{t}=\frac{T_{6}-T_{7}}{T_{6}-T_{7 i}}=\frac{\text { actual turbine work }}{\text { isentropic turbine work }}$

The ACM turbine useful work is calculated as:
$W_{t}=\dot{m} C_{p}\left(T_{6}-T_{7}\right)=\dot{m} C_{p} T_{6}\left[1-\left(\frac{P_{7}}{P_{5}}\right)^{\frac{k-1}{k}}\right] \eta_{t}$

The implicit equation resultant from the ACM work balance is given by:

$W_{s c}=\alpha\left(W_{t}\right)$

where $\alpha$ indicates the percentage of the ACM turbine work absorbed by the secondary compressor. The available work to drive the heat exchanger exhaust fan is equal to $(1-\alpha) W_{t}$.

Inserting Eq. (14) and Eq.(19) into Eq. (20), the implicit equation that provides the $P_{5}$ value is determined as:

$$
\begin{aligned}
& \frac{\dot{m} C_{p} T_{4 b}}{\eta_{s c}}\left[\left(\frac{P_{5}}{P_{4}}\right)^{\frac{k-1}{k}}-1\right] \\
& -\alpha\left\{\dot{m} C_{p} T_{6}\left[1-\left(\frac{P_{7}}{P_{5}}\right)^{\frac{k-1}{k}}\right] \eta_{t}\right\}=0
\end{aligned}
$$

when $\alpha=0$, the exhaust fan consumes all the ACM turbine work (simple cycle) and for $\alpha=1$, the secondary compressor absorbs the whole turbine work (bootstrap cycle).

Typically, the aircraft air conditioning system has a mixture chamber, where the cool air at temperature $T_{7}$ provided by the air cycle machine is mixed with the cabin recirculated air, which has been cleaned with high efficiency filters. This mixed air is then insufflated into the cabin through the ducting system. Therefore, the cooling effect of the air cycle machine $\left(Q_{c}\right)$ can be calculated as:

$Q_{C}=\dot{m} C_{p}\left(T_{\text {cabin }}-T_{7}\right)$

where $T_{\text {cabin }}$ is the cabin recirculated air temperature.

A portion of the primary compressor work must be attributed to the cabin pressurization system. This power work is used to increase the external air pressure to an adequate value that satisfies the human breathing requirements attaining a desirable occupants comfort level (usually a pressure value in the 8,000 feet level in the standard atmosphere, Figure 1). Hence, the cabin pressurization work $\left(W_{p}\right)$ is expressed by:

$W_{p}=\frac{\dot{m} C_{p} T_{2}}{\eta_{p c}}\left[\left(\frac{P_{7}}{P_{2}}\right)^{\frac{k-1}{k}}-1\right]+W_{r}$

The coefficient of performance (COPP) for the simple/bootstrap cycle, including the pressurization work, can be evaluated as:

$C O P P=\frac{Q_{c}}{W_{r}+W_{p c}}$ 
Excluding the pressurization work (Eq. 23), the coefficient of performance (COP) for the simple/bootstrap cycle is calculated by:

$$
C O P=\frac{Q_{c}}{W_{r}+W_{p c}-W_{p}}
$$

The equation set represented by Eq. (1) to Eq.(25) was solved employing a mathematical software with a friendly programming environment [19]. The obtained results will be herein discussed in the next section.

\section{Results and Discussion}

\subsection{Influence of Flight and Cabin Parameters}

The present paper analyzed the influence of Mach number, exhaust fan power, cabin pressure and cabin temperature on the ACM coefficient of performance (COP). Numerical values adopted for these flight and cabin parameters which have been used in each simulation are listed in Table 1 (test cases A and B) and Table 2 (test cases C and D).

Table 1. Restrictions to test cases A and B

\begin{tabular}{lll}
\hline & A test & B test \\
\hline Mach number & 0.47 to 1.18 & 0.47 \\
Exhaust fan power & $\alpha=1$ & $0 \leq \alpha \leq 1$ \\
Cabin pressure & $8,000 \mathrm{ft}$ & $8,000 \mathrm{ft}$ \\
$\begin{array}{l}\text { Cabin recirculated air } \\
\text { temperature }\end{array}$ & $24 \mathrm{C}$ & $24 \mathrm{C}$ \\
\hline
\end{tabular}

Table 2. Restrictions to test cases $C$ and $D$

\begin{tabular}{lll}
\hline & C test & D test \\
\hline Mach number & 0.47 & 0.47 \\
Exhaust fan power & $\alpha=1$ & $\alpha=1$ \\
Cabin pressure & 6,000 to $8,000 \mathrm{ft}$ & $8,000 \mathrm{ft}$ \\
$\begin{array}{l}\text { Cabin recirculated air } \\
\text { temperature }\end{array}$ & $24^{\circ} \mathrm{C}$ & 18 to $30^{\circ} \mathrm{C}$ \\
\hline
\end{tabular}

The ambient static conditions (point 1, in Figure 3) were maintained constant as shown in Table 3. Also, the ACM turbine and compressors efficiencies, the ram air compression efficiency, the bleed port pressure and temperature values (point 3a, Figure 3), as well the heat exchangers effectiveness were simulated with constant values (Table 3).

Table 3. Constant parameters in the simulations.

\begin{tabular}{lll}
\hline & A test & B test \\
\hline$T_{1}=-57 \mathrm{C}$ & $P_{1}=20 \mathrm{kPa}$ & $P_{3}=250 \mathrm{kPa}$ \\
$P_{4}=200 \mathrm{kPa}$ & $T_{3 \mathrm{~b}}=\mathrm{T}_{4 \mathrm{a}}=200 \mathrm{C}$ & $\eta_{\mathrm{t}}=0.77$ \\
$\eta_{\mathrm{r}}=0.84$ & $\eta_{\mathrm{pc}}=\eta_{\mathrm{sc}}=0.82$ & $\varepsilon_{\mathrm{phx}}=\varepsilon_{\mathrm{shx}}=0.80$ \\
\hline
\end{tabular}

Figure 5 shows the "A test" results (Table 1 ) for the Mach number effect on the ACM performance. The increase in the Mach number reduces both coefficients of performance previously defined as COPP (Eq. 24) and COP (Eq. 25). When the flight velocity elevates the stagnation temperature $\mathrm{T}_{2}$ increases, that is, the minimum attainable heat sink fluid temperature. This fact reduces the amount of rejected heat in the ACM heat exchangers.
The influence of the percentage of the ACM turbine power absorbed by the exhaust fan on the coefficient of performance is presented in Figure 6 ("B test" in Table 1). As the exhaust fan power consumption increases, the power available to the secondary compressor decreases lowering the temperature and pressure at the point 5 (Figure 3). Consequently, the rejected heat in the secondary heat exchanger decreases and the pressure difference available to the turbine expansion is lower. This implies in a reduction of the both coefficients of performance as can be seen in Figure 6.

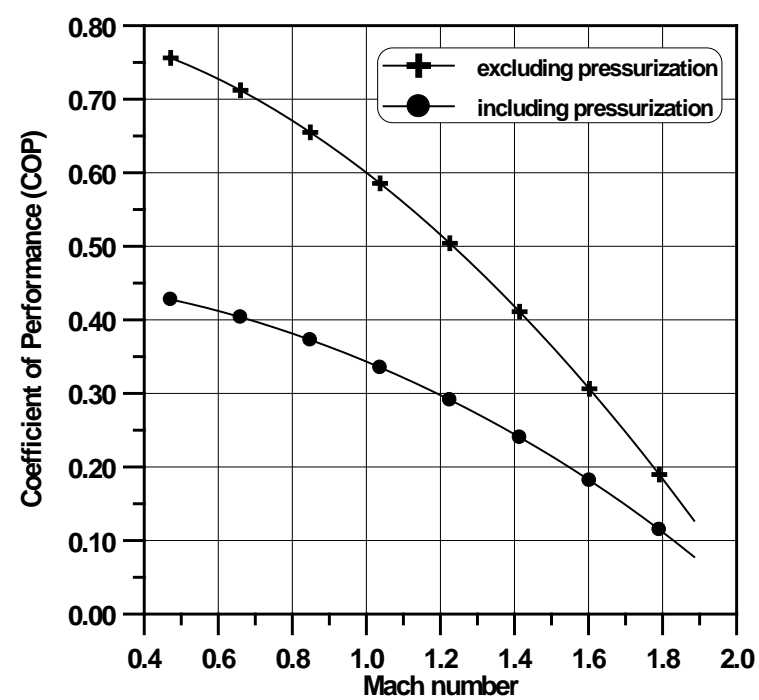

Figure 5. Coefficient of Performance as a function of the aircraft Mach number

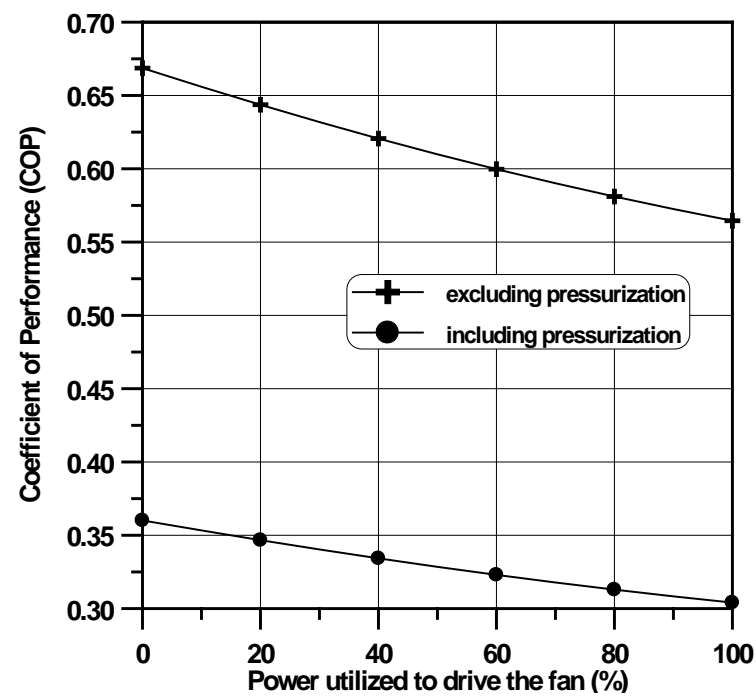

Figure 6. Coefficient of Performance as a function of the power required to drive the fan.

Figure 7 illustrates the "C test" results (Table 2) for the cabin pressure effect on the ACM performance. Higher values of cabin altitude (lower cabin pressure) increase the ACM turbine power. When this power is used by the secondary compressor, an elevation in the temperature and pressure of the state 5 occurs (Figure 3). This implies in an increase in the amount of rejected heat in the secondary heat exchanger causing a temperature $T_{7}$ reduction. Thus, the cooling effect increases the Eq. (24) numerator affecting the $C O P P$ value.

On the other hand, the coefficient of performance excluding the pressurization work presents a decrease because the Eq. (25) denominator increases with the cabin 
altitude elevation ( $W_{p c}$ is constant but $W_{p}$ decreases when the cabin altitude increases, see Figure 8 ) and this effect impacts on the numerator increase previous discussed.

The cabin recirculated air temperature influence on the ACM performance is shown in Figure 9. When the remaining parameters do not change ("D test" in Table 2), the increase in the $T_{\text {cabin }}$ value causes an elevation in the cooling effect Eq. (22) and, consequently, elevates both coefficients of performance.

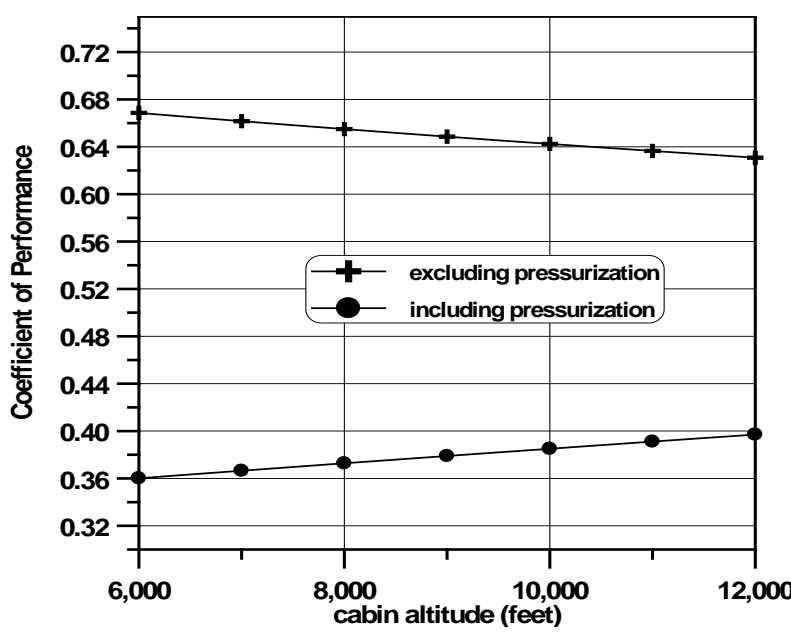

Figure 7. Coefficient of Performance as a function of the aircraft cabin altitude

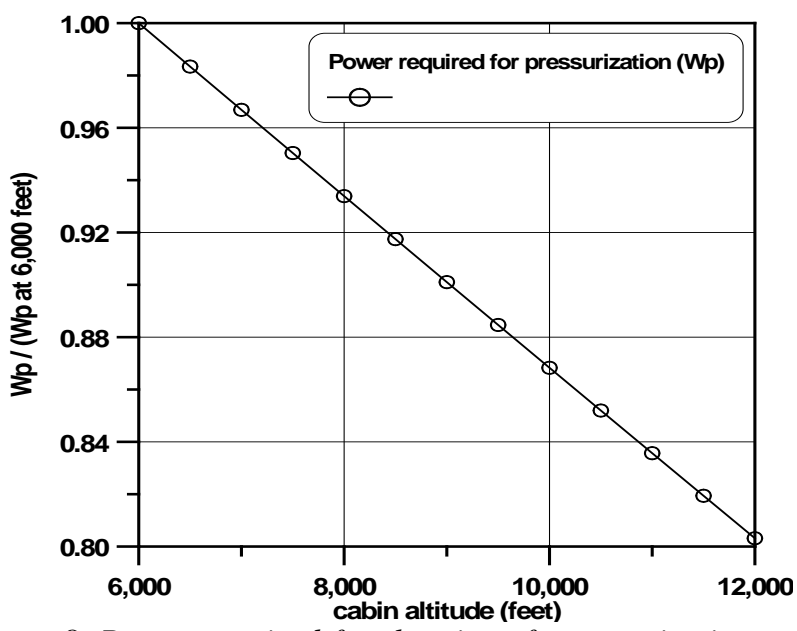

Figure 8. Power required for the aircraft pressurization as a function of the aircraft cabin altitude.

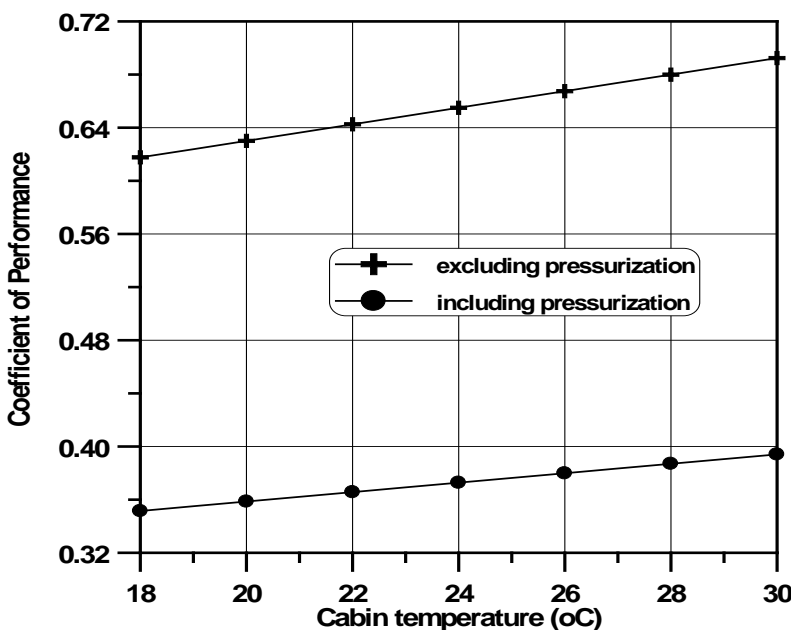

Figure 9. Coefficient of Performance as a function of the aircraft cabin recirculated air temperature.

\subsection{Typical flight mission employing bootstrap ACM}

In the present section, the air cycle machine coefficient of performance $(C O P)$, excluding the pressurization work, has been analyzed for a complete flight mission employing the bootstrap architecture (Figure 2b). Climb, cruise and descent modes totalize 4,000 seconds, as indicated Figure 10 .

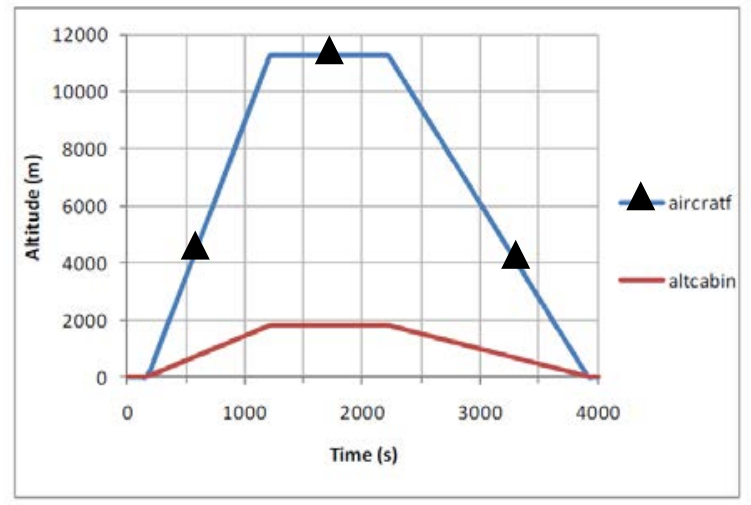

Figure 10. Typical flight mission

Note that the cabin and external altitude profiles vary along the flight duration, but while the aircraft cruise altitude is around $11,000 \mathrm{~m}(36,000 \mathrm{ft})$, the internal cabin level is close to the $1,800 \mathrm{~m}(6,000 \mathrm{ft})$. This pressure differential is typical of a commercial transport aircraft and is determined by combining the fuselage structural restrictions and cabin comfort requirements. Simulations were carried using the parameters listed in Table 3 . The cabin recirculated air was considered equal to $30^{\circ} \mathrm{C}$.

During the flight mission, the external temperature varies as a function of the altitude following the ISA atmosphere profile [1], as shown in Figure 11. Ambient temperature decreases along the climb mode and decreases as the aircraft descends. Cruise external temperature is almost $220 \mathrm{~K}\left(\sim-50^{\circ} \mathrm{C}\right)$.

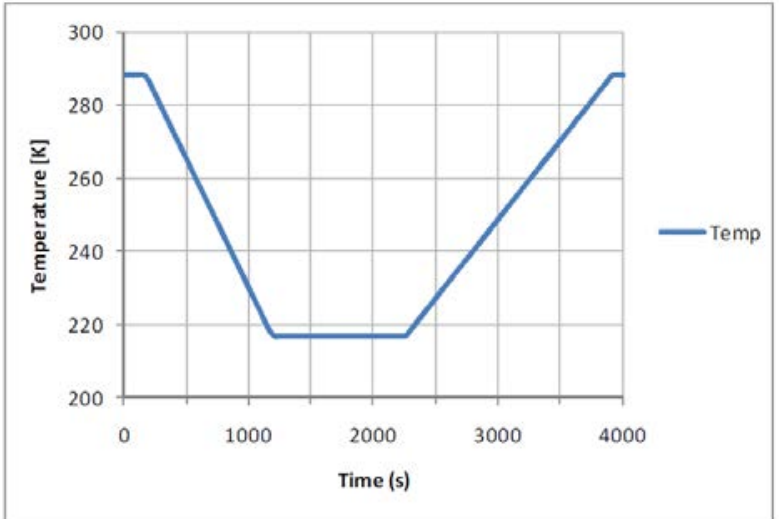

Figure 11. Ambient external temperature as a function of time-during flight.

Figure 12 shows the ACM performance parameters during the flight mission duration. First at all, it can be observed that the primary compressor work $\left(W_{p c}\right)$ presents the highest magnitude in comparison with the other computed quantities. It occurs due to the high pressure level achieved at the primary compressor exit (process 2-3a, in Figure 3). On the other hand, the ram work $\left(W_{r}\right)$ has the smallest magnitude and is almost constant during the aircraft flight mission. The cabin cooling effect $\left(Q_{c}\right)$ provided by the four-wheel air cycle machine also presents 
little variation during the flight time-evolution. Moreover, the cabin pressurization work $\left(W_{p}\right)$ curve follows the aircraft altitude profile (Figure 9a), reaching maximum values during the cruise mode.

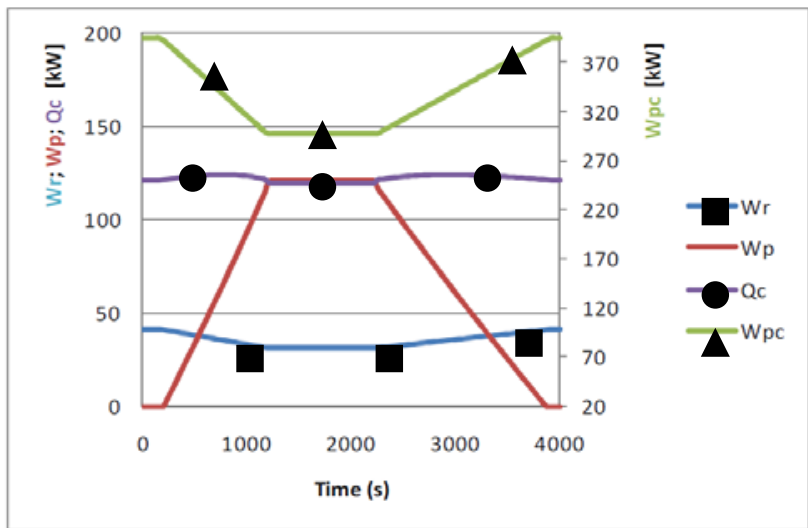

Figure 12. Bootstrap ACM performance during the flight mission $\left(W_{r}=\right.$ ram work; $W_{p}=$ pressurization work; $Q_{c}=$ cabin cooling effect; $W_{p c}=$ primary compressor work).

Even at the cruise mode, when the primary compressor power work $\left(W_{p c}\right)$ value is minimum $(\sim 300 \mathrm{~kW})$, its magnitude is higher in comparison with the other computed parameters. This fact has a great impact in the COP and COPP distributions, see Eq. (24) and Eq. (25), because a combined effect occurs: the cooling effect $\left(Q_{c}\right)$ curve behavior is practically constant $(\sim 120 \mathrm{~kW})$, the ram work $\left(W_{r}\right)$ has a low magnitude resulting that the primary compressor work $\left(W_{p c}\right)$ becomes the predominant factor in determining $C O P$ and $C O P P$ profiles shown in Figure 13.

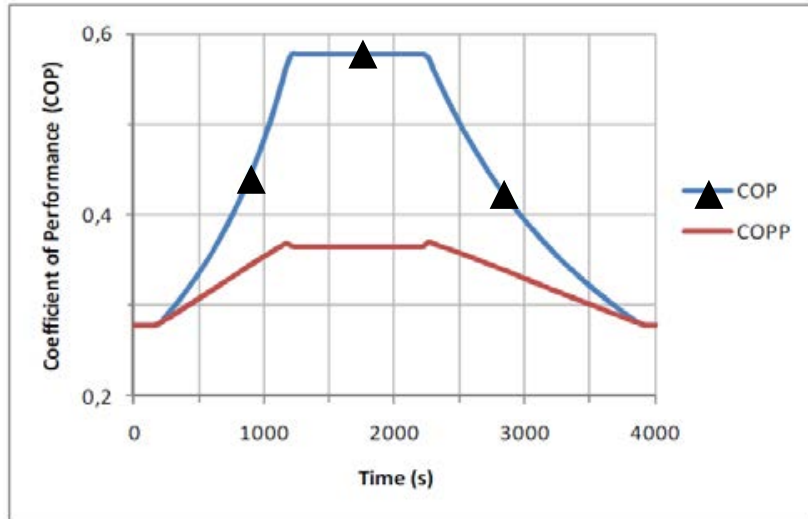

Figure 13. COP and COPP profiles employing the bootstrap ACM.

As the aircraft altitude increases (and the external pressure decays during the climb mode), both $C O P$ and $C O P P$ values increases affected mainly by the primary compressor work $\left(W_{p c}\right)$ magnitude decay. The opposite effect occurs during the descent mode. Therefore, $C O P$ and COPP maximum levels correspond to the primary compressor work $\left(W_{p c}\right)$ minimum level during the cruise flight mode.

\section{Concluding Remarks}

This paper presented a computational tool that solves the ACM mathematical model (thermodynamic cycle analysis) and allows an understanding of the ACM performance when flight aircraft and cabin human comfort parameters have been changed. In addition, the bootstrap air cycle machine behavior has been tested during a typical flight mission showing that:

i. The primary compressor work has the major impact on the ACM computed coefficient of performance.

ii. The useful ACM turbine work is used to provide the cabin pressurization work and refrigerant effect and, during the cruise mode, these two last parcels have practically the same magnitude (Figure 12).

iii. During the climb mode, the ACM performance enhances because primary compressor work decreases while the bleed port pressure conditions are unchanged along the flight mission. The opposite effect occurs during the descend mode.

\section{Nomenclature}

ACM Air Cycle Machine

COP Coefficient of Performance

COPP Coefficient of Performance including the pressurization work

$C_{p} \quad$ Specific heat at constant pressure, $\mathrm{kJ} / \mathrm{kg} / \mathrm{K}$

$C_{v} \quad$ Specific heat at constant volume, $\mathrm{kJ} / \mathrm{kg} / \mathrm{K}$

$\dot{\mathrm{m}} \quad$ mass flow rate, $\mathrm{kg} / \mathrm{s}$

$\mathrm{Ma} \quad$ Mach number

$P \quad$ Pressure, $\mathrm{Pa}$

$Q_{c} \quad$ Cooling effect, W

$Q_{p h x} \quad$ Primary heat exchanger rejected heat, $\mathrm{W}$

$Q_{\text {shx }} \quad$ Secondary heat exchanger rejected heat, W

$T \quad$ Temperature, $\mathrm{K}$

$W_{p} \quad$ Cabin pressurization work, $\mathrm{W}$

$W_{p c} \quad$ Primary compressor work, $\mathrm{W}$

$W_{s c} \quad$ Secondary compressor work, W

$W_{r} \quad$ Ram work, W

$W_{t} \quad$ ACM useful turbine work, $W$

\section{References}

[1] ASHRAE Handbook. HVAC Applications, American Society of Heating, Refrigerating and Air-Conditioning Engineers, Inc., Atlanta, GA, 2007.

[2] Lombardo, D. Aircraft Systems, McGraw Hill Publishing Company Limited, New York, USA, 1999.

[3] Hunt, E.H. and Space, D.R., The Airplane Cabin Environment, International In-flight Service Management Organization Conference, Montreal, Canada, 1994.

[4] Arici, O., Yang, S. Huang, D., and Oker, E. Computer Model for Automobile Climate Control System Simulation and Application, Int. J. Thermo., 2, 56-68, 1999.

[5] SAE, Society of Automotive Engineers, ARP292c, Environmental Control Systems for Helicopters, 1998.

[6] Garrett, A. D. Aircraft Systems \& Components, Jeppesen Sanderson Inc., Englewood, Colorado, USA, 1991.

[7] Moir, I., Seabridge, A. Aircraft Systems: Mechanical, Electrical, and Avionics, Subsystems Integration, AIAA Education Series, Professional Engineering Publishing, 2001.

[8] Arora, C. P. Refrigeration and Air Conditioning, Tata McGraw-Hill Publishing Company Limited, New Delhi, India, 726 p.,1988. 
[9] Leo, T.J. and Pérez-Grande, I. A thermoeconomic analysis of a commercial aircraft environmental control system Appl. Thermal Eng., 25, 309-325, 2005.

[10] Conceição, S.T., Zaparoli, E.L. and Turcio, W.H.L. Thermodynamic Study of Aircraft Air Conditioning Air Cycle Machine: 3-wheel x 4-wheel. Proceedings of SAE Brazilian Congress, Society of Automotive Engineers, 2007.

[11] Al-Garni, A. Z., Tozan, M. and Abdelrahman, W. G. Graphical Techniques for Managing Field Failures of Aircraft Systems and Components, J. Aircraft 46, 608616, 2009.

[12] Zhao H., Hou Y., Zhu Y., Chen L., Chen S. Experimental study on the performance of an aircraft environmental control system. Applied Thermal Engineering. 29, 3284-3288, 2009.

[13] Tu, Y. and Lin, G.P. Dynamic Simulation of Aircraft Environmental Control System Based on Flowmaster, Journal of Aircraft, 48(6) 2031-2041, 2011.

[14] Yoo, Y., Lee, H., Min, S. Hwang, K. and Lim, J. A Study on a Modeling and Simulation Program of an Environmental Control System with a Phase Change Heat Exchanger, AIAA Modeling and SimulationTechnologies Conference, Portland, Orego, USA, 2011.
[15] Hunt, E.H., Reid, D.H., Space, D.R. and Tilton, F.E., (), Commercial Airliner Environmental Control System, Aerospace Medical Association Annual Meeting, Anaheim, California, 1995.

[16] Wu, C. and Ahmed, N.A. Numerical Study of Transient Aircraft Cabin Flowfield with Unsteady Air Supply, J. Aircraft, 48, 1994-2001, 2011.

[17] Wright S., Andrews G., Sabir H., (). A review of heat exchanger fouling in the context of aircraft airconditioning systems, and the potential for electrostatic filtering. Appl. Thermal Eng., 29, 2596-2609, 2009.

[18] Dimopoulos, G. G., Frangopoulos, C. A. Effect of Gas-Properties Evaluation Method on the Optimum Point of Gas Turbine Cycles. Int. J. Thermo., 8, 95-102, 2005.

[19] Mathcad, Mathcad Reference Manual, MathSoft Inc, Cambridge, MA, USA, 1999. 